\title{
Analysis on Construction Technology of New Prefabricated Residential Buildings
}

\section{Fuyong Huang}

Liaoningjianzhu Vocational University, Liaoning, Liaoyang, 111000

Keywords: prefabricated; residential construction; construction technology

\begin{abstract}
Nowadays, the active development of the Ministry of Housing and Urban-Rural Development is driving the continuous advancement of industrialization of buildings. In this situation, the prefabricated building is particularly important and is the core embodiment of the industrialization of the building. The new type of prefabricated building can not only avoid the problems of social production in traditional construction industry, such as unreasonable social production, unreasonable energy utilization and environmental pollution, but also effectively improve the construction quality under the premise of reducing production costs. This is a new type of prefabricated residential building that uses modular design, factory manufacturing, and on-site workshop assembly, making it a difficult construction method. This paper studies the construction technology of prefabricated houses, and hopes to provide reference and help for related projects.
\end{abstract}

\section{Introduction}

Nowadays, with the deepening of urbanization, more and more buildings are becoming more and more, the construction industry is getting more and more people's attention, and the industry standards of the construction industry are gradually improving, aiming at achieving industrialization of buildings. The main purpose of the development of industrialization of buildings is to improve social production efficiency and labor productivity, improve backward production methods, and upgrade various levels of standardization, factoryization, mechanization and informationization. In terms of technology and management, the project construction quality will be improved and the construction speed will be effectively accelerated under the premise of ensuring the safety of construction workers, while reducing energy consumption and carbon emissions. The standardization of building design, the production of parts and components, the assembly of on-site construction, the integration of main structure and the informationization of management process are all important manifestations of the industrialization of new buildings. As prefabricated building works are increasingly respected by the construction industry, the corresponding safety and quality requirements are also raised. This is a relatively new construction method, but China's industrialization started late, all aspects of measures and technology are not perfect, and relevant safety management norms are not mature enough to form a set of standard industry norms, which also seriously hindered the construction. The industrialization process also requires a large number of research applications and development and promotion.

\section{Characteristics of Construction Technology of New Prefabricated Residential Building}

In recent years, China's research on prefabricated building structure system is still in the process of continuous advancement, and is gradually implemented in some practical engineering construction, such as prefabricated concrete assembly monolithic frame structure system and prefabricated monolithic concrete shear wall. From the perspective of development, promoting the continuous innovation of the system is an important part of the development of prefabricated building structures. From the practical point of view, it is difficult to implement, especially the prefabricated construction techniques of the vertical members of the main structure, such as shear walls, frame columns and various types of beams. By combining various building technologies with prefabricated structures, you can better highlight its advantages. 
Due to the long construction period of traditional construction projects, the production activities of nearby residents are seriously affected, and the inconvenience of transportation is also caused. Moreover, traditional buildings generally complete the hole-cutting within one or two months after the main structure is capped. Sub-frame closing, waterproof treatment and other work items. However, the new prefabricated residential building construction technology uses wooden bricks when installing the outer wall of the wall. This can ensure that the outer casing can be closed after the building is capped in the shortest time, and the construction work is also reduced. The installation of the insulation layer, the application of the anti-cracking mortar, the decoration of the exterior wall and the like in the prefabricated bay window and the prefabricated exterior wall complete the installation of the decorative layer and the insulation layer, shortening the construction period of at least three months. Because the weight of the assembled building is much lighter than that of the traditional building, the foundation is also simplified. After the factory sends the prefabricated building components, the workers can assemble them on site according to the map, which greatly improves the work efficiency and replaces the large-scale work of mud, plastering and wall-building in the past.

The construction method of the new prefabricated residential building construction technology is directly prefabricated by the manufacturer. The fabricated building exterior wall board is manufactured by the mold, mechanized spraying and steaming process, and then transported to the construction site for assembly by the workers. This is also the characteristic of the new prefabricated residential building construction technology. It belongs to the flow-through work process, the work content is simple, easy, short-time, and has high reproducibility. After repeated operations, as workers' proficiency in their work content continues to increase, their work efficiency is also guaranteed. Moreover, the prefabricated house adopts a flexible split between the large open spaces, and can be divided into living rooms of different sizes according to the individual needs of the residents. The home has a flexible opening, one of the main problems is to equip the matching lightweight partition wall, and the light steel keel with gypsum board or other light board is the best material for the partition wall and ceiling. The benefit of direct prefabrication by the factory is that construction costs are largely saved. Combined with the above analysis, compared with the relevant construction units, the new prefabricated residential building construction technology has greater advantages in actual construction than traditional buildings, which are reflected in time, manpower and resource requirements, and can Increase profits to some extent.

With the continuous development of the social economy, people's requirements for housing construction are getting higher and higher. In some earthquake-prone areas, the seismic capacity of houses is particularly important. Obviously, if the house has better earthquake resistance, it can effectively reduce casualties to a certain extent. The new prefabricated residential building construction technology can solve these problems to a large extent and meet people's requirements for housing construction. Because this new construction technology is the assembly of prefabricated components, using a lot of lightweight materials, reducing the weight of the building, increasing the flexible connection of the assembly, the structural strength is high, and the large part of the seismic resistance of the house depends on the structural strength. In this regard, its security has been significantly improved compared to traditional architecture. In addition, the exterior of the new prefabricated residential building is generally insulated with insulation material, which enhances the airtight-ness of the entire room and improves the sealing function of the wall and doors and windows. The thermal insulation material has a sound absorption function and effectively blocks the interference of external noise, but also achieved the effect of warm winter and cool summer, to minimize the energy consumption of winter heating and summer air conditioning, but also played a role in energy conservation. Moreover, the concrete-concrete residential building adopts reinforced concrete throughout the construction process, following the construction principle of rigid and soft, so the whole house structure is not easily affected by thermal expansion and contraction, which increases the service life of the house. . 


\section{Problems in the Application Process at the Current Stage}

At present, China's mastery of new prefabricated residential building construction technology is still not mature enough, and there are still many problems in the actual operation of various projects. After a series of investigations and summaries, the author lists the following problems and deficiencies in the actual operation of concrete-assembled residential building construction technology.

\subsection{Lack of Management and Protection of Construction Materials.}

The state has relevant requirements for various types of buildings, and its demand for building materials must meet national standards. Otherwise, it will become a dangerous building. Whether it is in the construction process or after the completion of construction, it will be buried for people's lives and property. Hidden dangers, once an accident occurs, will cause irreparable losses and impacts. In order to ensure the quality of residential buildings, a series of preparations and investigations must be carried out before the construction of concrete-assembled residential buildings. A detailed and detailed inspection of the selected building materials is carried out to check whether the quality has reached the corresponding level. . For these theoretical requirements, in many practical construction projects, they have not been well implemented and practiced, and there are still a series of problems and accidents caused by inadequate management of building materials. Therefore, the relevant building units should arrange special personnel to be responsible for the management and protection of materials throughout the selection, transportation and construction of building materials, and conduct relevant investigations on the manufacturers of building materials to ensure their production quality and level, so as to reduce the problem. Appear to prevent accidents.

\subsection{The Low Technical Level of Construction Workers.}

It can be seen from the above that this new type of prefabricated residential building construction technology does not have high requirements for the staff, but this is also limited to a certain extent. In some construction projects, there will still be some untrained staff who have certain defects and deficiencies in both technical and theoretical aspects, which in some ways induce problems such as project quality. Therefore, relevant departments should pay attention to it. For construction workers who do not fully grasp the construction technology of new prefabricated residential buildings, they cannot participate in construction projects.

\section{Measures to Improve the Engineering Quality of New Prefabricated Residential Buildings}

Combined with the above-mentioned articles, the author puts forward the following suggestions on how to improve the engineering quality of the new prefabricated residential buildings in the practical application process of the new prefabricated residential building construction technology in China.

Although this is a new type of prefabricated residential building construction technology, it has many similarities with traditional architectural methods. In the pipeline laying, the new prefabricated residential buildings require safe and reliable standards for the laying of pipelines during construction, and corresponding fixing measures are adopted for this purpose. In the pipeline laying, the wire box arrangement is adopted instead of the close parallel arrangement, which effectively avoids the phenomenon of three-dimensional cross crossing and pipeline conflict in the key interspersing.

All components of the new prefabricated residential building construction technology are prefabricated by the manufacturer, which means that the requirements for the pedestal grinding tools will be higher. Because the accuracy of the pedestal has directly affected the quality level of the prefabricated components, the general abrasive tools are made of steel and concrete pedestals. In this respect, there are also related production requirements. The abrasive tools must be operated with the surface of the pedestal being smooth and smooth, and the error should not exceed two 
millimeters.

Doing a good job in concrete maintenance is one of the important tasks to ensure the quality of the project. Because of the new prefabricated residential building technology, the floor area of the building houses is large, which leads to the serious loss of water. Therefore, relevant departments should arrange special personnel to do concrete maintenance work to ensure the quality of the project to the utmost.

In order to ensure construction safety, the new scaffolding and lifting platform system replaces the traditional scaffolding. This scaffolding multi-functional safety protection system is simple in structure, less in material consumption, light in weight, simple in disassembly, quick in construction and convenient in operation. The lifting platform system is more suitable for high-altitude construction than traditional external scaffolding, such as the construction of glass curtain wall and the decoration of the exterior wall of high-rise buildings. The project is mainly people-oriented. During the construction process, employees must end a number of special technical trainings before the post to enhance the technical level and concept of the staff, and timely conduct surveys and inspections on the construction site to ensure that the project can be the discipline science is carried out smoothly to ensure the quality of the project.

\section{Conclusion}

The development of the construction industry will tend to be industrialized in construction. Technology, energy conservation and pollution-free are the development trends and directions of the current and future construction industry. The new prefabricated residential building construction technology has the characteristics of short construction period, low cost and high performance, contributing to the construction of a green and environmentally friendly society, and is a good example for the entire construction industry. Under this circumstance, quality control and civilized safety are particularly important in the implementation of new prefabricated residential building construction technology. At the same time, we must continue to innovate and use advanced science and technology to drive the development of China's construction industry. Although China does not have a sound system for this new technology at present, in view of its considerable development prospects, if it can be widely applied, it will help solve the resource shortage phenomenon in our country and conform to China's sustainable development strategy.

\section{References}

[1] LIU Hongliang.GAO Jie.Prefabricated Building Structure System and Design [J].Journal of Shanghai Institute of Technology (Natural Science Edition), 2015, 15(04):357-361.

[2] JIANG QinJian.Overview of the development of fabricated concrete buildings at home and abroad [J].Architectural Technology, 2010, 41(12).

[3] Liu Xiaoyan.Zhang Yiqing.Discussion on Prefabricated Building Structure System and Design [J].Residential and Real Estate, 2016(06):219.

[4] ZHOU Tianhua. WU Hanheng. Steel frame-prefabricated concrete anti-side wall assembly structure system [J]. Journal of Building Science and Engineering, 2013, 30(03): 1-6.

[5] Zhang Haiyan. Shen Qiyu. Research on Construction of New Precast Concrete Structure System in Hong Kong [J]. Architecture Technology, 2009, 40(08). 